\title{
Adesão ao tratamento da Hanseníase: dificuldades inerentes aos portadores*
}

\author{
Adhesion to Leprosy treatment: inherent difficulties of the patients \\ Adhesión al tratamiento de la Lepra: dificultades inherentes a los portadores
}

Izaildo Tavares Luna', Eveline Pinheiro Beserra', Maria Dalva Santos Alves', Patrícia Neyva da Costa Pinheiro'

'Universidade Federal do Ceará. Programa de Pós-graduação em Enfermagem. Fortaleza, CE

Submissão: 07/09/2009

Aprovação: 12/09/2010

\section{RESUMO}

Esta pesquisa, realizada em Guaiúba, CE, Brasil, objetivou identificar as dificuldades de adesão ao tratamento pelos portadores de hanseníase, relacionando os fatores associados. Estudo Qualitativo, cujos dados foram coletados a partir de uma visita domiciliária com roteiro de entrevista contendo sete Questões norteadoras. Participaram pacientes com diagnóstico de hanseníase e histórico de não adesão ao tratamento. Utilizou-se o Modelo de Atividade de Vida de Roper, Logan e Tierney. As falas dos sujeitos foram categorizadas de acordo com as doze atividades de vida. A utilização do modelo possibilitou uma abordagem holística sobre as barreiras vivenciadas pelo hanseniano na adesão ao tratamento medicamentoso, de modo a conhecer as atividades de vida destes pacientes para possível adeQuação de ações voltadas a essa clientela.

Descritores: Hanseníase; Modelos de enfermagem; Recusa do paciente ao tratamento; Uso de medicamentos.

\section{ABSTRACT}

This research, carried in Guaiúba, Ceará, Brazil aimed to identify the difficulties for the treatment compliance of leprosy patients, relating the associated factors. This is a Qualitative study; data was collected from a home visit in January 2009 using an interview guideline containing seven guiding Questions. Diagnosed leprosy patients with history of non compliance to treatment participated of the study. It was used Roper, Logan and Tierney's Model of Life Activities. The speeches of the subjects were classified according to twelve life activities. The model utilization made possible a holistic approach on the barriers lived by leprosy patients in the compliance to drug treatment, in order to know the life activities of these patients to a possible adaptation of the actions addressed to this clientele. Key words: Leprosy; Models nursing; Treatment refusal; Drug utilization.

\section{RESUMEN}

Esta investigación, llevada a cabo en Guaiúba, CE, Brasil, tuvo el objetivo de identificar las dificultades de la adhesión al tratamiento para las personas con lepra, relacionándoles a los factores associados. Estudio cualitativo, donde los datos fueron colectados a través de una visita domiciliaria mediante entrevista con siete preguntas guía. Participaron los pacientes con diagnóstico de lepra y con historia de no adherencia al tratamiento. Se ha utilizado el modelo de actividad de vida de Roper, Logan y Tierney. Los discursos de los sujetos fueron clasificados de acuerdo con las doce actividades de la vida. La utilización del modelo permitió un abordaje holístico acerca de las barreras experimentadas por los portadores de lepra en la adhesión al tratamiento farmacológico, de modo a conocer las actividades de vida de estos pacientes para posibles adecuaciones de acciones destinadas a esta clientela.

Descritores: Lepra; Modelos de enfermería; Negativa del pacientes al tratamiento; Utilización de medicamentos.

* Trabalho extraído da monografia "Adesão ao tratamento da hanseníase: dificuldades inerentes aos portadores" do curso de Especialização em Vigilância Epidemiológica das Doenças Transmissíveis pela Escola de Saúde Pública do Ceará-ESPCE.

AUTOR CORRESPONDENTE Izaildo Tavares Luna. Rua Carlos Vasconcelos, 1847, Apto 303. CEP 601 15-171. Fortaleza, CE. E-mail: izaildo@ufc.br 


\section{INTRODUÇÃO}

A hanseníase é uma moléstia causada por um micróbio - bacilo de Hansen o Qual ataca a pele e os nervos, conhecida também como "lepra”, "morféia”, "mal-do-sangue". Trata-se de doença contagiosa e curável. Talvez por ser uma doença contagiante e que pode acarretar terríveis deformações, os portadores sempre foram discriminados e muitos sofreram o abandono, sendo postos em lugares afastados do convívio social ${ }^{(1)}$.

No Brasil, a partir dos anos de 1950, teve início a utilização de medicamentos eficazes no combate à hanseníase, desta forma, desenvolveu-se a certeza de Que o relacionamento social não trazia riscos para a população e os benefícios para o doente eram enormes, permitindo-o uma reintegração à sociedade.

Percebe-se Que mesmo com os avanços ocorridos no diagnóstico, controle e tratamento da hanseníase, ainda é nítido o estigma da doença, provocado pelo preconceito, medo e pelas rejeições por parte da sociedade.

QualQuer indivíduo Que apresente manchas esbranquiçadas ou avermelhadas na pele, com formigamentos e perda definida de sensibilidade, deve ser considerado um caso de hanseníase ${ }^{(2)}$.

Sintomas e sinais manifestam-se através das lesões na pele com perda de sensibilidade, decorrente de processos inflamatórios. As neurites surgem de processo agudo, seguido de intensa dor e edema. Essas lesões são acometidas por transtornos do sistema nervoso periférico, afetado pelo mycobacterium leprae. A hanseníase tem um período de incubação muito longo, durando de 3 a 5 anos. $\mathrm{O}$ mycobacterium leprae se multiplica de maneira lenta, afetando principalmente a pele, os nervos e os músculos.

As pesquisas na área de combate à hanseníase têm demonstrado a necessidade efetiva de preparar métodos Que promovam, a partir de ações práticas, mudanças significativas para a eliminação da doença como problema de saúde pública no Brasil( ${ }^{(3)}$.

Considerando a hanseníase como um grave problema de saúde pública e importante causa de incapacidades e deformidades em portadores não tratados, este estudo apresentou o seguinte Questionamento: Quais as dificuldades de adesão ao tratamento pelo portador de Hanseníase?

Portanto, esta pesquisa objetivou identificar as dificuldades na adesão ao tratamento pelos hansenianos, relacionando os fatores associados por meio do Modelo de Atividade de Vida de Roper, Logan Tierney.

Compreende-se Que o conhecimento das dificuldades enfrentadas na adesão ao tratamento da hanseníase é imprescindível para subsidiar uma assistência mais humanizada e de Qualidade, implicando na promoção de ações de saúde Que se traduzam nas resoluções dos problemas identificados, na satisfação e na garantia de uma assistência integral. Em um contexto mais amplo, colaborará para o desenvolvimento de políticas de saúde direcionadas à valorização da prática de educação em saúde, representando um processo capaz de modificar o comportamento, desenvolvendo no indivíduo o senso de responsabilidade por sua saúde e pela saúde da comunidade a eual pertença.

\section{MÉTODO}

Estudo de abordagem Qualitativa, pois envolve compreensões acerca dos acontecimentos, vivências únicas dos sujeitos, influências pela cultura e pelas percepções construídas ao longo da vida ${ }^{(4)}$.

Foi realizado em três Unidades de Saúde da Família (USF), localizadas na cidade de Guaiúba-Ceará, município Que integra a região metropolitana de Fortaleza, tem como estratégia de organização da atenção primária o Programa Saúde da Família (PSF), atual Estratégia Saúde da Família (ESF) com nove equipes de saúde da família/saúde bucal.

Os sujeitos foram seis pacientes usuários do serviço de atenção básica com diagnóstico confirmado de hanseníase apresentando histórico de não adesão precoce ao tratamento medicamentoso da doença. Os participantes foram submetidos à entrevista norteada pelas Questões: como foi para você saber Que tinha hanseníase? Quais as orientações recebidas sobre o tratamento para obter a cura? Quais os motivos Que o levaram a não iniciar o tratamento? Você conhece alguma pessoa próxima Que faz o tratamento? O Que ela conta? O Que lhe impede de fazer o tratamento? Como você pode obter a cura da doença sem tomar medicamentos? O Que a sua família tem feito por você Quando soube do diagnóstico?

O estudo foi encaminhado, inicialmente, ao Comitê de Ética em Pesquisa, da Escola de Saúde Pública do Ceará, conforme Resolução 196/96, do Conselho Nacional de Saúde, do Ministério da Saúde, com aprovação sob o número 146/2008.

Os participantes do estudo foram esclarecidos sobre o objetivo da pesquisa, sendo garantido o sigilo das informações, com o direito de desistir a eualquer momento de participar da pesquisa, em Qualeuer uma de suas etapas. Foi apresentado a cada participante o Termo de Consentimento Livre e Esclarecido, assinado por todos.

Os dados foram coletados em de janeiro de 2009, por meio de uma visita domiciliária com posterior aplicação de um roteiro de entrevista. Utilizou-se como mês de janeiro de 2009.referencial teórico para análise dos dados o Modelo de Atividade Vida, proposto Roper, Logan e Tierney, Que busca a identificação das principais características do viver, seu significado e as inter-relações entre os componentes do modelo ${ }^{(5)}$.

Este modelo consta de doze atividades de vida: manter um ambiente seguro; comunicar; respirar; comer e beber; eliminar; higiene pessoal e vestir-se; controlar a temperatura corporal; mobilizar-se; trabalhar e distrair-se; exprimir sexualidade; dormir; morrer. Para a análise das falas, utilizaram-se estruturas categóricas prontas, relacionadas às dozes atividades de vida e agregadas às falas.

\section{RESULTADOS E DISCUSSÃO}

Foi entrevistado um grupo de seis pacientes, nos Quais Quatro eram do sexo masculino e dois do sexo feminino. Quanto à ocupação, três sujeitos eram aposentados, um não trabalhava e os outros dois estavam empregados. No Que refere à idade, três estavam na faixa etária acima dos 60 anos, um acima de 50 anos e dois apresentavam idade entre 30 e 40 anos. No que concerne à escolaridade, um havia concluído o Ensino Fundamental, três não conseguiram concluir e dois nunca estudaram.

Atividade de vida por pacientes com diagnóstico de hanseníase

As atividades de vida dependendo do enfoeue dado podem ser vista sob aspectos variados, até mesmo com uma atividade global 
repleta de particularidade. Como evidenciado, os componentes desta complexidade confirmam Que há uma íntima relação das atividades de vida. Estas atividades podem ser observáveis, escritas e medidas. Entretanto, momentos vividos em diferentes contextos criam prioridades distintas, repercutindo na importância das atividades de vida para cada paciente, sendo as mesmas influenciadas por fatores físicos e psico-sociais, ambientais e político-econô$\operatorname{micos}^{(5)}$.

Detalha-se nas seções a seguir, com dados Qualitativos, as atividades de vida realizadas pelos pacientes com diagnóstico de hanseníase e Que não aderiram precocemente ao tratamento medicamentoso. Assim, para cada atividade de vida, perceberamse as principais alterações relatadas, como também se observou no contexto as dificuldades enfrentadas por cada sujeito e sua íntima relação com as condições de vida e saúde.

\section{Atividade de vida - manter um ambiente seguro}

Para a atividade de vida manter um ambiente seguro, encontrase uma variedade de dimensões, das Quais, elencaram-se as ações preventivas, Que contribuem para a segurança do ambiente físico, como a prevenção de acidentes. As medidas de educação em saúde são cruciais nesta prevenção. Essa atividade de vida deve ser lembrada mesmo durante o trabalho. $\mathrm{O}$ ato de prevenir infecções como também a compreensão dos fatores relacionados aos tipos de infecção estão incluídas nessa atividade. Cada indivíduo deve desenvolver conceitos próprios de responsabilidade e zelo pessoal por si e para com os outros ${ }^{(5)}$.

Reconhece-se como condição para a manutenção de um ambiente seguro, aspectos de educação em saúde, o uso do medicamento para o tratamento da doença e a segurança dos familiares. Todos estes poderiam contribuir na melhoria dos cuidados voltados à higiene e ao processo saúde-doença.

Encontrou-se ainda um enredo comum entre os pacientes deste estudo para representar a experiência com o tratamento e a doença. Usando o termo "eu acho Que estas manchas devem sumir", compreenderam-se conteúdos de uma imagem desvinculada do tratamento como instrumento para o combate à enfermidade. Os pacientes ressaltaram a fé em Deus e Que o conhecimento sobre a doença, o tratamento, o autocuidado, a busca por um diagnóstico adeeuado, a obediência à orientação médica, as perguntas realizadas pelos médicos e o tratamento apropriado não têm importância na luta contra a enfermidade.

Os instrumentos de enfrentamento da doença não coincidiram com as orientações gerais sobre o tratamento, fornecidas pelos profissionais de saúde da área. Nos discursos dos pacientes, é nítida a não aceitação do tratamento medicamentoso como uma arma eficaz na luta contra o bacilo.

Eu não sei se existe algum remédio do mato Que serve para curar estas manchas, acho Que estas manchas deve sumir com o tempo se assim Deus Quiser. (E3)

Não comecei tomar remédio no começo não porQue pensei Que fosse besteira, Que fosse só uma coceira, mas vi Que não era só coceira não [...]. (E4)

Nas exposições dos sujeitos não-aderentes, encontrava-se fragilizada a atividade de vida manter o ambiente seguro, o Que implica em dúvida do paciente em relação ao diagnóstico médico. A partir desta observação, considera-se relevante a credibilidade na relação entre tratamento-sintoma e saúde-sintoma especialmente no caso da hanseníase, uma vez Que necessita de uma reconstrução para resgatar a confiança do portador da hanseníase na adesão ao tratamento para obter a cura e prevenir as deformações ocasionadas pela não adesão ao tratamento medicamentoso.

O modelo de Enfermagem subsidia a construção de um plano de cuidados, baseado no aspecto físico, social e necessidades emocionais, gerando itens Que sustentam a sua utilização na prática, aspectos também observados em estudo realizado com recémnascidos $^{(6)}$. Embora estes sejam sujeitos diferentes, o estudo evidenciou a contribuição do modelo para um modo investigativo da realidade.

Com resultados como esses, é possível direcionar um cuidado específico, sabe-se Que da importância da terapêutica medicamentosa da hanseníase para a cura da doença. No caso de paciente com diagnóstico de hanseníase, a não aceitação do uso de poliquimioterápico (PQT) influencia a continuidade da corrente de transmissibilidade da doença, interferindo na adequada manutenção do ambiente seguro, podendo provocar danos nas outras atividades de vida, como mobilizar-se, comunicar-se e trabalhar e distrair-se, o Que comprova Que as atividades de vida estão interligadas e que uma influencia a outra.

No Que concerne à manutenção do ambiente seguro, o uso do PQT e a continuidade do autocuidado representam fatores Que contribuem para a segurança do paciente e dos familiares, pois às vezes o contato dos comunicantes com o portador não tratado torna o ambiente propício à continuidade da cadeia de transmissão da enfermidade.

Desse modo, percebe-se Que o uso do PQT facilita sobremaneira a cura da doença. Atualmente, há maior preocupação dos profissionais em orientar o paciente Quanto à importância da medicação como ferramenta para obter a cura da hanseníase.

Sobre esta Questão, têm-se os seguintes relatos:

O médico disse que devo tomar remédios, se não tomar os comprimidos vai ficar pior, pode complicar minha vida, tinha Que fazer exames e tomar as pílulas todo dia. (E2)

O doutor que mim atendeu disse que tenho que dar toda importância a minha saúde, é como eu estar fazendo um bem pros meu e pra todo o mundo. Tenho que tomar remédios, porQue é preciso vencer o problema. (E5)

A adesão ao tratamento integral da hanseníase exige Que o paciente assuma muitos compromissos, pois é parte essencial da cura e deve estar consciente disso, pois aderir ao tratamento consiste em um processo Que depende de três fatores: a percepção da importância dos objetivos a atingir, a probabilidade de Que a ação levará ao objetivo e o esforço requerido ${ }^{(7)}$.

\section{Atividade de vida - comunicar}

A comunicação permeia a relação dos seres humanos em sociedade. A atividade de comunicar promove o relacionamento interpessoal e é componente do comportamento humano. O 
comunicar-se constitui uma atividade influenciada por crenças, atitudes, valores, experiências anteriores e antecedentes sociais. Quando ao longo da vida ocorre a ausência de relações interpessoais confiáveis, poderá ocorrer a falta de autoconfiança. Esta atividade de vida poderá ser avaliada por meio de observação, perguntas diretas ao paciente ou informantes-chave e registros ${ }^{(5)}$.

Ao abordar esta atividade de vida a intensidade do comunicarse no ambiente domiciliário, reflete-se a presença de relações interpessoais embasadas pela confiança, influenciando a estabilidade emocional do paciente, uma vez que a hanseníase é, historicamente, uma doença estigmatizante.

Ao referir a comunicação intradomiciliar do portador da hanseníase se remete a uma série de valores Que estão implícitos no estigma cultural da doença. Durante a comunicação, há troca de informações e, se todo o processo tiver sido explorado eficazmente, essa troca levará a conscientização do paciente, Que influenciará na decisão em assumir-se como doente e assim adQuirir as responsabilidades da adesão ao tratamento.

A presença de explicações a partir do imaginário social surge no discurso para conferir significado para aspectos ignorados da doença. Assim, um mesmo discurso apresenta ambos os conteúdos: aquele oriundo do saber médico e aquele proveniente do imaginário popular. Nas falas dos sujeitos, as teorias arcaicas da condenação divina, da hereditariedade e de miasmas parecem intensificar-se diante do discurso atual sobre a ação dos bacilos sobre o corpo. Porém, essa nova informação é compreendida de maneira superficial, permitindo Que a ideia da importância da adesão ao tratamento medicamentoso seja discutida entre os membros da família.

As minhas meninas ficam aperriadas, tiveram medo de Que as manchas passasse para elas. Dizem que se eu tomar o remédio, vão ajudar a eu lembrar de tomar. Minha mulher diz que sou teimoso, pois o remédio é dado e devo seguir o que o doutor disse e deixar de teimosia. (E I)

A dona Odete ela tá tratando, ela disse que ta quase boa, vive satisfeita, disse pra eu também tomar os comprimidos que o doutor passa e ter fé em Deus que fica logo boa. (E3)

Uma vez assistindo a televisão vi uma especialista dizendo que tinha um remédio, eu acho que o jatobá da serra fecha o corpo,combate anemia [...] sei não, acho Que resolve já tomei protege contra enfermidade. (E4)

Na maioria dos países, em Que a concepção de hanseníase era atrelada ao medo Quase constante, hoje percebido como uma doença esquecida, contudo com implicações Que podem ser limitantes ${ }^{(8)}$. Logo, a compreensão desses pacientes sobre a doença é importante para sua Qualidade de vida.

O processo de comunicação é constituído de diversos prismas e para Que sejam efetivados os tipos de comunicação, verbal ou não verbal, torna-se necessário ocorrer uma significação comum aos participantes. Através da comunicação, o profissional informará ao paciente sobre a doença, o tratamento, a cura e os mais variados assuntos, caso tenha interesse $\mathrm{e}^{(9)}$.

É pela comunicação verbal Que os profissionais da saúde interagem com o paciente. Também deve ser valorizada a linguagem não verbal percebida nas expressões faciais e corporais.

\section{Atividade de vida - comer e beber}

A alimentação e a ingestão de líuuidos são essenciais na vida diária, em todas as faixas de idade, e o interesse despertado pelo alimento e pelo líquido oferecido varia em cada indivíduo. Para esta atividade de vida, devem-se observar as influências sofridas pelos fatores socioculturais presentes na escolha do Que se come e bebe.

Atualmente, o alcoolismo representa um grave problema mundial, é insidioso e Quando presente interfere nos cuidados pessoais, nos comportamentos e na diminuição do apetite, com conseQuências para a saúde. Conforme as condições de cada pessoa pode-se beber moderamente. Mas, o álcool não deve superar 4\% da ingestão energética diária. $\mathrm{O}$ alcoolismo provoca mudanças nos hábitos alimentares ${ }^{(5)}$.

Diante destas considerações, nos sujeitos estudados, julgou-se Que a prática etilista pode ser um aspecto ocasiona comportamentos isento de responsabilidades, Quanto ao autocuidado e por consequência a não aceitação do tratamento medicamentoso.

Após a detecção da doença, a adesão ao processo terapêutico ou não, é fundamental mudança no estilo de vida, com adoção de hábitos saudáveis, sendo parte integrante do plano de cuidados, muitas vezes não compreendido pelo paciente.

As causas do alcoolismo podem ser consideradas multifatoriais, associadas a fatores bio-psico-sociais, Que se complementam na explicação etiológica do alcoolismo. Seu uso abusivo pode acarretar desordens orgânicas.

Nas falas, percebeu-se a preocupação dos pacientes em não poder associar consumo de álcool ao tratamento medicamentoso como fator Que dificulta a aceitação da terapêutica medicamentosa da hanseníase.

Os doutores disseram que estas manchas é hanseníase e que tenho de tomar remédios e não podia beber, eu tinha Que tomar direitinho pra ficar livre das manchas. (EI)

Ele disse que eu tenho que receber as medicações. O doutor falou que eu ia ficar bom, mas tenho Que parar de beber. (E4)

Consoante aos discursos, pôde-se inferir que o uso da bebida alcoólica revelou-se como um fator Que impossibilita tanto a adesão ao tratamento como a regularidade deste. Verificou-se que muitas vezes o álcool é visto pelo indivíduo como um recurso para encarar o cotidiano sem medo ou utilizar-se na busca pelo esquecimento das dificuldades vivenciadas.

Estudos observaram o comportamento de permanência sem o consumo o álcool estimula a pessoa a tomar uma decisão sob uma percepção negativa em relação à bebida ${ }^{(10)}$. Logo, os pacientes durante o tratamento necessitam perceber Que o consumo de álcool não permite um tratamento eficaz.

O aumento no consumo do álcool e a sua inserção em ambientes sociais e familiares, mesmo com todo o malefício comprovado pelo consumo dessa substância, muitas vezes está associado à superação de sentimentos como solidão e frustração(11).

\section{Atividade de vida - higiene pessoal e vestir-se}

Como a higiene e a boa aparência são recomendações da maioria 
das culturas, a ausência de uma higiene pessoal apropriada, poderá ocasionar afastamento social. A atividade de vida higiene e vestirse representa aspectos culturais e tradicionais, além de estarem associados à sexualidade, sendo uma forma de exacerbação da comunicação não verbal. De modo geral, a execução de atividades como o ato de banhar-se pode variar conforme o trabalho e lazer. Deve-se salientar Que a presença de algumas alterações no corpo poderá ocasionar rupturas teciduais, permitindo assim a entrada de microorganismo no sistema, provocando disfunções Que exigem tratamento ${ }^{(5)}$.

Em relação à prática relacionada à atividade de vida higiene pessoal e vestir-se, corroboram as falas Que seguem.

Esta mancha fica assim, vai e vem, muda de cor fica escura, o doutor disse que é hanseníase, não estou convencido não. (E3)

Disse o doutor que é comum o povo sentir este tipo de formigamento. Eu não sinto nenhum tipo de problema, acho Que é besteira, deve ser coceira Que peguei. (E2)

É relevante considerar Que os enfermeiros trabalham em diferentes contextos culturais e a percepção do cliente é um fator importante a ser ponderado ${ }^{(12)}$. Observou-se no discurso de E3 a crença em relação à doença.

No referente ao vestuário, o instrumento não contemplou essa Questão, mas a forma de vestir-se pode influenciar no processo saúde-doença. O uso de roupas apertadas dificulta a circulação sanguínea, o Que pode resultar em prejuízos para a saúde do indivíduo. Já o uso de roupas limpas, colabora para a absorção das impurezas expelidas pelo corpo ${ }^{(13)}$.

\section{Atividade de vida - mobilizar-se}

A capacidade de movimento de cada indivíduo está relacionada aos possíveis fatores Que podem influenciar na independência dessa atividade Que aborda a capacidade de movimento de cada sujeito, enfatizando aspectos físicos e psicológicos. Portanto, para os indivíduos Que sofrem de doenças ou lesão, seja temporária ou definitiva, tornam o paciente totalmente dependente de cuidados ${ }^{(5)}$.

Gosto de ir ao médico não, hoje mesmo a moça do posto Queria Que eu fosse lá, mais estas coisas de doutor pra mim demora e vivo com dor nas pernas, só saiu de casa Quando é preciso, ando muito pouco. (E5)

A moça vem aqui e diz Que devo ir ao posto, sou velho e sinto dor nas pernas, a doutora vem aqui em casa, mas sempre estou na minha roça. (E6)

Diante das falas, observou-se o aspecto cultural no Que se refere ao comparecimento ao posto, caracterizado pela insatisfação em relação ao atendimento médico e, na outra fala, a ocupação na roça. Torna-se preciso investigar as causas das dores nas pernas desses pacientes, contudo, é importante a prática de atividades de educação em saúde para o desenvolvimento do autocuidado, tomando como alicerce o contexto cultural do indivíduo. Diante destas, a Qualidade de vida das pessoas com alterações de mobilidade sofre complicações, relacionadas ao tempo e aos valores individuais, como percepções e sentimentos Que o indivíduo tem de si e dos outros. As alterações na mobilidade podem acarretar complicações na Qualidade de vida das pessoas, necessitando de intervenção ${ }^{(14)}$.

Os benefícios das atividades físicas favorecem ao bem-estar, e a prática de exercício em longo prazo resultar em saúde prolongada, aumentando a Qualidade de vida ${ }^{(15)}$.

\section{Atividade de vida - trabalhar e distrair-se}

O trabalho é descrito como principal atividade diária do indivíduo. Seus efeitos sobre a saúde podem ser positivos ou negativos, ou mesmo contribuir para o surgimento de doenças físicas ou psicológicas. lá a atividade de lazer diz respeito ao Que se realiza distante do tempo de trabalho, com vistas à distração( $0^{(5)}$.

A atividade de lazer favorece a promoção da saúde, visto Que otimiza a saúde e auxilia na prevenção de problemas de saúde. O lazer é um elemento essencial de promoção da saúde. Tem sido demonstrado Que pessoas Que mantêm momentos de distração reduzem significativamente o risco de doença cardiovascular, acidente vascular encefálico, fratura de Quadril, osteoporose e Quedas $^{(16)}$

Quanto às concepções do trabalho e da distração no cotidiano do portador da hanseníase, emergiram as seguintes falas:

Meu rapaz, sou velho e trabalho na roça, moro sozinho, a menina Que vem aqui em casa disse que tenho que tomar remédios todo dia e que não posso esquecer de tomar. Sabe, sou esquecido, Quando a gente fica velho tudo fica difícil,aí não lembro,saiu cedo para o roçado e só volto à noite. (E2)

Para falar a verdade eu trabalho num ramo muito corrido e tem dia que esqueço até que eu existo, tem dia que eu nem almoço, não tenho tempo pra lembrar de tomar remédio, não. (E4)

A verdade eu trabalho muito e tem dia Que nem lembro de comer. [...] disseram Que os comprimidos têm Que tomar certinho e como vou tomar se não lembro. (E5)

Verificou-se Que as atividades laborais diárias surgem com um fator Que dificulta a não adesão ao tratamento da hanseníase pelos portadores, pois na visão destes ao iniciar o uso do PQT, necessitarão de uma maior atenção aos horários das doses da medicação.

Há necessidade de uma maior atenção voltada às informações e orientações em saúde, como preocupação no investimento na informação e na educação do portador, por meio de intervenções Que permitam Que eles se conscientizem sobre a importância da adesão medicamentosa para obtenção da cura da doença ${ }^{(17)}$.

O estudo demonstra um grau considerável de descuido por parte do portador da hanseníase Quanto à necessidade do uso do PQT na luta contra a doença, o Que seria necessário investimento na atualização dos profissionais de saúde, discutindo, junto à equipe, o problema da não adesão e de suas causas, bem como as possibilidades de solução ${ }^{(18)}$.

A partir dos relatos dos sujeitos, faz-se necessário proceder junto ao portador da hanseníase de a uma abordagem multidisciplinar, visando à melhoria das informações orientações 
sobre a doença e o tratamento.

A doença impõe, com a sua descoberta, uma infinidade de mudanças, e o ser doente deverá estar apto a realizar as adaptações necessárias. Os profissionais Que atuam no acompanhamento do portador de hanseníase devem ser facilitadores dessas adaptações, buscando promover a saúde e o bem-estar do paciente.

A importância da prática de educação em saúde é notória e deve ser valorizada, pois representa um processo capaz de modificar o comportamento, objetivando desenvolver no indivíduo o senso de responsabilidade colocado em termos de escolhas comportamentais.

A crescente necessidade de se planejar, realizar e documentar o processo de ensino do portador de hanseníase como parte da assistência de rotina surge como exigências sociais ${ }^{(18)}$.

\section{Atividade de vida - dormir}

A atividade de vida dormir é importante, pois propicia descanso, refletindo na disposição e no bem-estar do indivíduo. As alterações no sono e repouso poderão estar associadas a fatores como preocupação, ansiedade e depressão. Uma pessoa sem um período de sono adequado pode desenvolver mal estar e até mesmo adoecer.

Problemas para dormir é comum em pessoas com doenças crônicas ou psíquicas, frecuentemente se atribuye a cambios Que la edad produce geralmente atribuídos às alterações Que o processo de adoecimento provoca en la arQuitectura del suen oy en el ritmo circadiano, perona areuitetura do sono e no ritmo circadiano, podendo produzir mudanças significativas no padrão de sono, levando ao surgimento de distúrbios do sono, como a insônia ${ }^{(19)}$.

Contudo, há uma enorme variação na determinação dos padrões de sono suficiente para cada indivíduo, pois cada pessoa tem seu tempo próprio de sono. A capacidade individual de dormir e o descansar sofrem influencia de todos os tipos de situações, Que caracterizam o sono e repouso como uma atividade sensível e individualizada $^{(5)}$.

Em relação a essa atividade de vida, foram observadas as seguintes falas:

Absolutamente, logo via dizer Que o medicamento deixa nervoso, sente falta de sono, fica com o fígado ruim, é um monte de remédio pra tomar na hora certa, tenho tempo para isso não. (E4)

É porque Quando tomo remédio fico com o estomago mal, tenho diarréia, o meu fígado doe e fico noites sem dormir. Aí tenho medo deste monte de comprimido prejudicar. (E6)

Nos relatos acima, notou-se a associação dos entrevistados Quanto ao uso do PQT e a alterações provocadas no ciclo de sonovirgília. A associação da insônia a reações do medicamento tornase nítida, pois o não dormir é visto pelos sujeitos como um grave problema.

Dentre os distúrbios do sono, a insônia foi apontada como a mais freeuente podendo ser primária ou secundária a distúrbios psiQuiátricos, orgânicos ou ingestão de substâncias ou drogas, por isso, é importante classificar as causas da insônia, estabelecendo adequadamente estratégia de intervenção ${ }^{(20)}$. A insônia acarreta pensamentos alterados e atividades comportamentais anormais, pois as funções do sistema nervoso central são afetadas pela falta de sono ${ }^{(21)}$.

O número de pessoas Que sofre de insônia é elevado, cerca de $16 \%$ a 40\%. Dormir é vital e favorece não apenas o descanso mental, mas também a ocorrência de processos metabólicos. No comprometimento dessa atividade, inúmeras conseQuências surgem, pois a privação do sono incentiva o indivíduo a apresentar redução do vigor físico, cansaço, sonolência, irritabilidade, alterações do humor, problemas cognitivos e alterações na produção de hormônios ${ }^{(22)}$.

\section{Atividade de vida -morrer}

Inevitavelmente, todas as atividades da vida são interrompidas com a morte. Ao se pensar na morte, sentimentos como ansiedade, inquietude e medo são despertados, na perspectiva da própria morte ou da morte de parentes. A ansiedade da morte é um reflexo do medo da morte e do Que acontece após, podendo ser definida como uma reação emocional, produzida pela percepção de sinais de perigo ou ameaça real ou imaginária ${ }^{(23)}$. O pesar neste contexto representa um processo necessário e doloroso, podendo levar anos para ser superado ${ }^{(24)}$.

Assim, eu via o povo falar nas manchas, eu não sabia Que está na minha perna fosse. Ela parece um caroço de milho, o doutor tirou um pedaço para exame, tive medo de ser câncer. Ele disse Que não era, Que era esta doença. (E2)

Apresentou uma mancha no meu braço, parecia um machucado A agente marcou uma consulta e eu fui procurar o médico ele disse que tenho a doença, naquela hora tive medo de ser coisa ruim. Fico achando que é um tipo de ferimento que logo vai sarar, o doutor disse que é hanseníase. (E3)

Na hora foi como uma confissão com o padre. Fiquei com medo, pensei vaila meu Deus vou morrer, foi o Que pensei na hora. Na minha luta fieuei nervoso.É difícil receber notícias ruim. (E5)

No início eu achava que era um machucado deixei para lá, entreguei nas mãos de Deus. Se for para eu ficar bom eu vou ficar. Tenho medo não, pois se for para morrer,vou morrer sempre Qualquer dia mesmo. (E6)

Os sujeitos entrevistados apresentaram representações semelhantes no Que se refere à atividade de vida morrer. A doença foi identificada por meio de seus sintomas, ou seja, manchas, caroços, dores, dormência, febre, deformidade física. Além disso, o medo do contágio/transmissão não está implicitamente caracterizado nos relatos dos entrevistados sobre a enfermidade. Ademais, a interpretação das manchas como sendo ferimentos e/ ou feridas e Que logo irão sarar, foi sinalizada em alguns casos, bem como o medo de maior gravidade da doença, citando, pois, o câncer. Não houve uma relação nítida entre o medo da doença e o conteúdo do conhecimento sobre as deformidades Que podem surgir com a não adesão ao tratamento da hanseníase.

A presença de explicações da cura da enfermidade a partir do imaginário religioso surgiu no discurso para conferir significado para aspectos ignorados da doença. Assim, um mesmo discurso apresentou os conteúdos: oriundo do saber médico e proveniente 
do imaginário popular.

A atual prática de cuidados de enfermagem no processo de morrer ainda está atrelada ao modelo médico ocidental, a morte é considerada como um inimigo e Quando isso acontece implica em uma falha no cuidado, gerando reações de frustrações emocionais como: medo, ansiedade e depressão(25).

Na maioria das vezes, as estratégias utilizadas pelos profissionais para o desenvolvimento do processo educativo sobre o adoecer e o morrer impõem o saber técnico como uma única verdade. Dessa forma, o paciente encara o processo como uma imposição de informações, não se sentindo estimuladas as mudanças e, ainda, as orientações confrontam-se com o saber popular.

As falas mostraram Que a educação em saúde deve ser abordada com maior intensidade entre os pacientes, para o desenvolvimento do autocuidado. Nesse contexto, a educação em saúde tem um papel importante. Não é o mero explicar, mas também ajudar o indivíduo a examinar as bases sociais de sua vida e de seu trabalho e tentar identificar os problemas de saúde em sua comunidade ${ }^{(26)}$.

A educação em saúde possibilita a aplicação de intervenções educativas relacionadas ao controle das emoções ajudando no lidar com a morte e o processo de morrer ${ }^{(27)}$, assim o sujeito terá condições físicas e psíeuicas para analisar sua situação real e descobrir seus problemas, encontrar soluções e assumir responsabilidades ${ }^{(28)}$.

A reflexão crítica do indivíduo e do grupo deve ser estimulada para Que haja o desenvolvimento da consciência das causas, dos problemas e das ações necessárias para a melhoria das condições. Somente desta forma a prática da educação demonstrará resultados condizentes com os objetivos traçados ${ }^{(29)}$.

O estudo não identificou nas atividades de vida respirar; eliminar; controlar a temperatura corporal; exprimir sexualidade a relação com á não adesão ao tratamento da hanseníase. Essas atividades são intrínsecas à vida humana. Contudo, para esses pacientes, elas não exerceram uma participação direta de acordo com as etapas de vida, para a obtenção dos dados Que conduzisse à identificação do nível de dependência/independência do cliente.

\section{CONSIDERAÇÕES FINAIS}

Com base no objetivo do estudo, os resultados motivaram a compreensão de Que os portadores de hanseníase Que não apresentaram histórico de adesão ao tratamento medicamentoso, demonstraram a presença de fatores Que intervieram no adequado desenvolvimento de suas atividades de vida. A utilização do Modelo de Atividade de Vida, como instrumento adaptado à visita domiciliária permitiu uma abrangência aos aspectos fundamentais a serem investigados. Os achados foram relevantes, porque proporcionaram um maior conhecimento acerca das dificuldades Que interferem nas atividades de vida desempenhadas pelos sujeitos do estudo.

$\mathrm{Na}$ atividade de vida manter um ambiente seguro, identificou-se a fragilidade na credibilidade por parte do paciente Quanto ao diagnóstico médico e a não aceitação do uso de PQT como ferramenta para a obtenção da cura da doença. Esses achados sugerem a necessidade de uma maior atenção por parte dos serviços em saúde de trabalhar a orientação dos portadores, despertando neles a consciência de Que a adesão ao tratamento de forma objetiva e continuada o trará a obtenção da cura da enfermidade.

A atividade comunicar foi marcada pela presença de explicações a partir da imaginação popular, ignorando os aspectos científicos oriundo do conhecimento médico nas comunicações intrafamiliares. As informações acerca da importância da adesão ao tratamento medicamentoso foram compreendidas de maneira superficial. Portanto, torna-se necessária a construção de uma comunicação sob diversos prismas, efetivando uma maior interação entre profissional e paciente.

Em relação à atividade comer e beber, observou Que a prática etilista incentiva o comportamento isento de responsabilidade Quanto ao autocuidado e, por conseguinte, a impossibilidade da adesão ao tratamento medicamentoso como a regularidade deste.

$\mathrm{Na}$ atividade de vida higiene pessoal e vestir-se, a presença de alterações teciduais como manchas e formigamentos cutâneos podem ser sinais de rupturas teciduais ocorridas pela a entrada de microorganismo no sistema tegumentar, exigindo tratamento dermatológico.

Sobre a atividade de vida mobilizar-se, alguns relatos de dores nas pernas e a insatisfação Quanto à consulta médica surgiram como fatores passíveis de influência na dependência de cuidados. Quanto à atividade de vida trabalhar e distrair-se, as atividades laborais do dia a dia surgiram como fator principal Que dificultava a adesão ao tratamento medicamentoso pelos portadores, pois para eles o início do uso do PQT necessitava de uma maior atenção aos horários do remédio.

A atividade de vida dormir mostrou a nítida associação, realizada pelos pacientes, da insônia a reações do medicamento. Para os sujeitos, o ato de não dormir é um grave problema. Quanto à atividade de vida morrer, notou-se a presença de explicações de cura de enfermidade, partindo do imaginário religioso, não se observando uma relação entre o medo da doença e o conhecimento sobre as deformidades Que podem surgir com a não adesão ao tratamento. Nesse ponto, destaca-se Que a educação em saúde deve ser abordada intensamente entre os pacientes, para o desenvolvimento do autocuidado.

A utilização do Modelo de Atividade de Vida com enfoeue na visita domiciliária proporcionou uma investigação com abordagem holística, oferecida aos portadores de hanseníase, permitindo um conhecimento detalhado dos aspectos Que intervêm na manutenção de práticas e etilos saudáveis de vida.

Contudo, para Que as ações voltadas a esses sujeitos sejam eficazes, deve estar imbuída no conhecimento das dificuldades inerentes a não adesão ao tratamento por eles vivenciado. Para uma assistência holística, os serviços em saúde devem conhecer as atividades de vida dos portadores de hanseníase para direcionar as ações voltadas a essa clientela. Faz necessária a dissipação dos preceitos e estigmas, contribuindo para a melhoria da Qualidade no atendimento oferecido a estes indivíduos.

Desse modo, esta pesQuisa contribui para reafirmar Que a prática de Enfermagem em atenção primária Que exige do profissional enfermeiro a competência para tomar decisões, viabilizando intervenções compatíveis com as necessidades da clientela, sendo imprescindível reconhecer Que o cuidado ao indivíduo, à família e à comunidade requer uma visão direcionada cada vez mais para o cuidar humano.

É importante investigações como esta Que apresentou um modelo elaborado por enfermeiros Que propiciam o planejamento de ações educativas que estimulem o indivíduo ao autocuidado, de modo a desenvolver uma vida saudável. 


\section{REFERÊNCIAS}

1. Silva Júnior FIG, Ferreira RD, Araújo OD, Camêlo SMA, Nery IS. Assistência de enfermagem ao portador de Hanseníase: abordagem transcultural. Rev Bras Enferm 2008; 61 (esp):713-7.

2. Organização Mundial da Saúde. Guia para Eliminação da Hanseníase como problema de Saúde Pública. Genebra: OMS; 2000.

3. Ministério da Saúde (BR). Cadernos de Atenção Básica. Dermatologia na atenção Básica. Brasília: Ministério da Saúde; 2002.

4. Leopardi MT, Beck CLC, Nietsche EA, Gonzales RMB. Metodologia da Pesquisa na Saúde. Santa Maria: Pallotti; 2001 .

5. Roper N, Logan WW, Tierney AJ. Modelo de enfermagem. $3^{\mathrm{a}}$ ed. Portugal: Mcgrawhill; 1995.

6. Timmins F, O'Shea, I. The Roper-Logan-Tierney. Model of nursing as a tool for professional development in education. Nurse Educ Pract 2004; 4(3):159-67.

7. Claro LBL. Hanseníase: representações sobre a doença. Rio de Janeiro: Editora Fiocruz; 1995.

8. Ryan TI. Dermatology in the developing world: needs and solutions. Dermatol Clin 2000; 18(2): 20 I- 10.

9. Oriá MOB, Moraes LMP, Victor JF. A comunicação como instrumento do enfermeiro para o cuidado emocional do cliente hospitalizado. Rev Eletrôn Enferm 2004; 6(2):292-7.

10. Wing DM. Applying the "Model of Recovering Alcoholics' Behavior Stages and Goal Setting" to nursing practice. Arch Psychiatr Nurs 1993; 7(4):197-202.

11. Silva SED, Sousa MI. Alcoolismo: representações sociais de alcoolistas abstêmios. Esc Anna Nery Rev Enferm 2004; 8(3): 420-7.

12. Lancellotti K. Culture Care Theory: A framework for expanding awareness of diversity and racism in nursing education. I Prof Nurs 2008; 24(3):179-83.

13. White EG. A ciência do bom viver. $10^{\text {a }}$ ed. São Paulo: Casa Publicadora Brasileira; 2004.

14. Vall J, Braga VAB, Almeida PC. Estudo de Qualidade de vida com pessoas com lesão medular traumática. Are Neuro-Psieuiatr 2006; 64(2B): 45 I-5.

15. Spier BE, Meis M. Maintenance ambulation: Its significance and the role of nursing: a walking program not only can benefit frail elders, it also can raise the level of a nurse's awareness about the ability of a resident to ambulate. Geriatr Nurs 1994; 15(5):277-81.

16. Nahas MV. Atividade física, saúde e Qualidade de vida conceitos e sugestões para um estilo de vida. Londrina: Midiograf; 2006.

17. Dewulf NLS. Investigação sobre adesão ao tratamento medicamentoso em pacientes portadores de doenças inflamatórias intestinais [dissertação]. Ribeirão Preto: Faculdade de Medicina de Ribeirão Preto, Universidade de São Paulo; 2005.

18. Sampaio FPR, Pagliuca LMO. Transplantado renal um acompanhamento ambulatorial. Fortaleza: FCPC; 2000.

19. Byles I, Mishra G, Harris M, Fair K. The problems of sleep for older women: changes in health outcomes. Age Ageing 2003; 32: 154-63.

20. Quan S, Zee P. A sleep review of systems; evaluating the effects of medical disorders on sleep in the older patient. Geriatrics 2004; 59(3): 37-43.

21. Guyton AC, Hall JE. Tratado de fisiologia médica. I I a ed. Rio de Janeiro: Elsevier; 2006.

22. Cronfli RTA. A importância do sono. Revista Cérebro e Mente [Internet]. 2002 [citado em 2009 Mar I 5]; Disponível em: http:/ /www.cerebromente.org.br/n l6/opiniao/dormir-bem l .html.

23. Limonero IT. Ansiedad ante la muerte. Ansiedad y Estrés 1997; 3: 37-46.

24. Belsky J. The psychology of aging. Three Lakes: Cole Publishing Company; 1999.

25. Petit de Mange, ME. The story of Rabbia, a dying person. Holist Nurs Pract 1998; 13:76-81.

26. Stotz EM. Enfoques sobre educação e saúde. In: Valla VV, Stotz N. Participação popular,educação e saúde:teoria e prática. Rio de Janeiro: Relume-Dumará; 1993. p.I I-22.

27. Herrero AA, Sábado IT. Efectos de un programa de educación emocional sobre la ansiedad ante la muerte en estudiantes de enfermería. Enferm Clin 2006; 16(6): 32 1-6.

28. Esmeraldo MNB. Educação para a saúde nas comunidades de base [tese]. Crato: Faculdade de Filosofia do Crato; 1984.

29. Kawamoto EE, Mattos TM, Santos MCH. Enfermagem comunitária. São Paulo: EPU; 1995. p. 29-34. 